Pacific Journal of Mathematics

MONOTONE APPROXIMATION 


\title{
MONOTONE APPROXIMATION
}

\author{
O. SHISHA
}

How close can one approximate a monotone function by a monotone polynomial of degree $\leqq n$, or a convex function by a convex polynomial of degree $\leqq n$ ? This leads to the following general question. Let $k$ and $n$ be given, and suppose a real fuction $f$ satisfies $f^{(k)}(x) \geqq 0$ throughout a closed, finite interval $[a, b]$. How close can one approximate $f$ on $[a, b]$ by a polynomial of degree $\leqq n$ whose $k$ th derivative, too, is $\geqq 0$ there? We give an answer to the question.

2. THEOREM 1. Let $k$ and $p$ be integers, $1 \leqq k \leqq p$, and let $a$ real function $f$ satisfy throughout $[a, b]$

$$
\begin{aligned}
f^{(k)}(x) & \geqq 0, \\
\left|f^{(p)}\left(x_{2}\right)-f^{(p)}\left(x_{1}\right)\right| & \leqq \lambda\left|x_{2}-x_{1}\right|,
\end{aligned}
$$

$\lambda$ being a constant. Then for every integer $n(\geqq p)$ there exists a real polynomial $Q_{n}(x)$ of degree ${ }^{1} \leqq n$ such that

(a) $Q_{n}^{(k)}(x) \geqq 0$ throughout $[a, b]$,

(b) $\operatorname{Max}_{a \leqq x \leqq b}\left|f(x)-Q_{n}(x)\right| \leqq 2 \lambda\left(\frac{\pi}{4}\right)^{p-k+1}(b-a)^{p+1}\left[k ! \prod_{\nu=k}^{p}(n+1-\nu)\right]^{-1}$.

3. To prove Theorem 1 , we begin by quoting the following result of J. Favard [2] and N. Ahiezer and M. Krein [1] which strengthens a previous result of D. Jackson.

THeOREm 2. (Favard, Ahiezer-Krein) Let $f$ (with period 2 $\pi$ ) map the reals into the reals, and satisfy for every real $x_{1}, x_{2}$

$$
\left|f\left(x_{2}\right)-f\left(x_{1}\right)\right| \leqq \lambda\left|x_{2}-x_{1}\right| \text {, }
$$

$\lambda$ being a constant. Then for $n=0,1,2, \cdots$, there exists a trigonometric polynomial $T_{n}(x) \equiv \sum_{\nu=0}^{n} a_{\nu}^{(n)} \cos \nu x+b_{\nu}^{(n)} \sin \nu x$ such that $\max _{0 \leqq x \leqq 2 \pi}\left|f(x)-T_{n}(x)\right| \leq \lambda(\pi / 2)[1 /(n+1)]$.

From Theorem 2 one obtains by the method of [3], pp. 13-14 the following

THEOREM 3. Let $f$ be a real function satisfying (1) throughout $[a, b], \lambda$ being a constant. Then for $n=0,1,2, \cdots$, there exists $a$

Received March 17, 1964.

${ }_{1}$ By degree of a polynomial we mean its exact degree. (The degree of the polynomial 0 is -1 ). 
polynomial $P_{n}(x)$ of degree $\leqq n$ such that

$$
\max _{a \leqq x \leqq b}\left|f(x)-P_{n}(x)\right| \leqq \lambda \frac{\pi}{4} \frac{b-a}{n+1} .
$$

For future use, we make the following simple observation. (Compare [3], p. 16).

LEMma. Let $f$ be a real function, continuous in $[a, b]$ and differentiable in $(a, b)$. Let $n$ be an integer $(\geqq 0), q_{n-1}(x)$ a real polynomial of degree $\leqq n-1$, and let $\varepsilon$ be such that $\left|f^{\prime}(x)-q_{n-1}(x)\right|$ $\leqq \varepsilon$ throughout $(a, b)$. Then there exists a polynomial $P_{n}(x)$ of degree $\leqq n$ such that

$$
\max _{a \leqq x \leqq b}\left|f(x)-P_{n}(x)\right| \leqq \varepsilon \frac{\pi}{4} \frac{b-a}{n+1} .
$$

To prove the lemma, set $r(x) \equiv f(x)-\int_{a}^{x} q_{n-1}(t) d t$. Throughout $(a, b),\left|r^{\prime}(x)\right| \leqq \varepsilon$, and therefore, throughout $[a, b],\left|r\left(x_{2}\right)-r\left(x_{1}\right)\right| \leqq$ $\varepsilon\left|x_{2}-x_{1}\right|$. By Theorem 3, there exists a polynomial $\pi_{n}(x)$ of degree $\leqq n$ such that $\max _{a \leqq x \leqq b}\left|r(x)-\pi_{n}(x)\right| \leqq \varepsilon(\pi / 4)(b-a) /(n+1)$. Setting $P_{n}(x) \equiv$ $\pi_{n}(x)+\int_{a}^{x} q_{n-1}(t) d t$, we obtain (2).

From Theorem 3 and the Lemma one gets readily (cf. [3], pp. 16-17) the following

THEOREM 4. Let $f$ be a real function satisfying throughout $[a, b]$, for some constant integer $p(\geqq 0)$ and some constant $\lambda$,

$$
\left|f^{(p)}\left(x_{2}\right)-f^{(p)}\left(x_{1}\right)\right| \leqq \lambda\left|x_{2}-x_{1}\right|
$$

Then for every integer $n(\geqq p)$ there exists a polynomial $P_{n}(x)$ of degree $\leqq n$ such that

$$
\max _{a \leqq x \leqq b}\left|f(x)-P_{n}(x)\right| \leqq \lambda\left[\frac{\pi}{4}(b-a)\right]^{p+1}\left[\prod_{\nu=0}^{p}(n+1-\nu)\right]^{-1} .
$$

3. Proof of Theorem 1. Let $n$ be an integer $\geqq p$. Set $f_{n}(x) \equiv$ $f^{(k)}(x)+\lambda[(\pi / 4)(b-a)]^{p-k+1}\left[\Pi_{\nu=k}^{p}(n+1-\nu)\right]^{-1}$. Then throughout $[a, b]$, $\left|f_{n}^{(p-k)}\left(x_{2}\right)-f_{n}^{(p-k)}\left(x_{1}\right)\right| \leqq \lambda\left|x_{2}-x_{1}\right|$. By Theorem 4, there exists a real polynomial $P_{n-k}(x)$ of degree $\leqq n-k$ such that

$$
\max _{a \leqq x \leqq b}\left|f_{n}(x)-P_{n-k}(x)\right| \leqq \lambda\left[\frac{\pi}{4}(b-a)\right]^{p-k+1}\left[\prod_{\nu=k}^{p}(n+1-\nu)\right]^{-1} .
$$

So, throughout $[a, b], P_{n-k}(x) \geqq f^{(k)}(x) \geqq 0$. Let 


$$
Q_{n}(x) \equiv\left[\sum_{\nu=0}^{k-1} \frac{f^{(\nu)}(a)}{\nu !}(x-a)^{\nu}\right]+\int_{a}^{t_{k+1}} \int_{a}^{t_{k}} \cdots \int_{a}^{t_{2}} P_{n-k}\left(t_{1}\right) d t_{1} d t_{2} \cdots d t_{k}
$$

( $t_{k+1}$ being here and below, $x$ ). Then $Q_{n}(x)$ is a real polynomial of degree $\leqq n$, and $Q_{n}^{(k)}(x)=P_{n-k}(x) \geqq 0$ throughout $[a, b]$. Furthermore, throughout that interval, we have

$$
f(x)=\left[\sum_{\nu=0}^{k-1} \frac{f^{(\nu)}(a)}{\nu !}(x-a)^{\nu}\right]+\int_{a}^{t_{k+1}} \int_{a}^{t_{k}} \cdots \int_{a}^{t_{2}} f^{(k)}\left(t_{1}\right) d t_{1} \cdots d t_{k},
$$

and therefore

$$
\begin{aligned}
\left|f(x)-Q_{n}(x)\right| & \leqq \int_{a}^{t_{k+1}} \int_{a}^{t_{k}} \cdots \int_{a}^{t_{2}}\left|f^{(k)}\left(t_{1}\right)-P_{n-k}\left(t_{1}\right)\right| d t_{1} \cdots d t_{k} \\
& \leqq 2 \lambda\left[\frac{\pi}{4}(b-a)\right]^{p-k+1}\left[\prod_{\nu=k}^{p}(n+1-\nu)\right]^{-1} \frac{(x-a)^{k}}{k !} \\
& \leqq 2 \lambda\left(\frac{\pi}{4}\right)^{p-k+1}(b-a)^{p^{+1}}\left[k ! \prod_{\nu=k}^{p}(n+1-\nu)\right]^{-1} \cdot
\end{aligned}
$$

4. The following Theorem 5 deals with a somewhat more general situation than that of Theorem 1.

THEOREM 5. Let $k$ and $p$ be integers, $1 \leqq k \leqq p$, and let a real function $f$ satisfy throughout $[a, b]$

$$
\begin{aligned}
f^{(k)}(x) & \geqq 0, \\
\left|f^{(p)}(x)\right| & \leqq M,
\end{aligned}
$$

$M$ being a constant. Let $\omega(x)$ be the modulus of continuity of $f^{(p)}$ in $[a, b]$. Then for every integer $n(\geqq p)$ there exists a real polynomial $Q_{n}(x)$ of degree $\leqq n$ such that

$$
\begin{aligned}
& Q_{n}^{(k)}(x) \geqq 0 \quad \text { throughout }[a, b], \\
& \max _{a \leqq x \leqq b}\left|f(x)-Q_{n}(x)\right| \\
& \leqq 2\left(1+\frac{\pi}{4}\right)\left(\frac{\pi}{4}\right)^{p-k}(b-a)^{p}\left[k ! \prod_{\nu=k}^{p-1}(n+1-\nu)\right]^{-1} \omega\left(\frac{b-a}{n-p+1}\right)
\end{aligned}
$$

(an "empty" product means always 1).

Theorem 5 is proved by means of the following Theorem 6 , in the same way that Theorem 1 was proved by means of Theorem 4 .

THEOREM 6. Let $f$ be a real function having a bounded $p$ th $(p \geqq 0)$ derivative throughout $[a, b]$. Let $\omega(x)$ be as in Theorem 5 . Then for every integer $n(\geqq p)$ there exists a polynomial $P_{n}(x)$ of degree $\leqq n$ such that throughout $[a, b]$ 


$$
\left|f(x)-P_{n}(x)\right| \leqq\left(1+\frac{\pi}{4}\right)\left[\frac{\pi}{4}(b-a)\right]^{p}\left[\prod_{\nu=0}^{p-1}(n+1-\nu)\right]^{-1} \omega\left(\frac{b-a}{n-p+1}\right)
$$

5. Theorem 6 follows from Theorem 3 by Jackson's method ([3], pp. 15-18). For the reader's convenience we hereby prove Theorem 6 in full. We do it by induction on $p$. Suppose first $p=0$. Let $n$ be an integer $(\geqq 0)$. Let $\phi(x)$ be the function whose graph is obtained by joining successively the points $\left(\xi_{\nu}, f\left(\xi_{\nu}\right)(\nu=0,1, \cdots, n+1)\right.$ of the $x, y$ plane, where $\xi_{\nu}=a+[(b-a) /(n+1)] \nu$. For $\nu=1,2, \cdots, n+1$ we have $\left|\phi\left(\xi_{\nu}\right)-\phi\left(\xi_{\nu-1}\right)\right| \leqq \omega[(b-a) /(n+1)]$. Hence, if $a \leqq x_{1}<x_{2} \leqq b$, then

$$
\frac{\left|\phi\left(x_{2}\right)-\phi\left(x_{1}\right)\right|}{x_{2}-x_{1}} \leqq \frac{n+1}{b-a} \omega\left(\frac{b-a}{n+1}\right) .
$$

By Theorem 3 , there exists a polynomial $P_{n}(x)$ of degree $\leqq n$ such that throughout $[a, b]$

$$
\left|\phi(x)-P_{n}(x)\right| \leqq \frac{n+1}{b-a} \omega\left(\frac{b-a}{n+1}\right) \frac{\pi}{4} \frac{b-a}{n+1}=\frac{\pi}{4} \omega\left(\frac{b-a}{n+1}\right) .
$$

Clearly, for every $x \in[a, b],|f(x)-\phi(x)| \leqq \omega[(b-a) /(n+1)]$. Therefore, throughout $[a, b],\left|f(x)-P_{n}(x)\right| \leqq[1+(\pi / 4)] \omega[(b-a) /(n+1)]$. This proves Theorem 6 when $p=0$. Suppose the theorem was proved for some $p-1(\geqq 0)$. We shall prove it for $p$. Let $n$ be an integer $(\geqq p)$. By our hypothesis there exists a polynomial $P_{n-1}(x)$ of degree $\leqq n-1$ such that throughout $[a, b]$

$$
\begin{aligned}
\mid f^{\prime}(x) & -P_{n-1}(x) \mid \\
& \leqq\left(1+\frac{\pi}{4}\right)\left[\frac{\pi}{4}(b-a)\right]^{p-1}\left[\prod_{\nu=1}^{p-1}(n+1-\nu)\right]^{-1} \omega\left(\frac{b-a}{n-p+1}\right) .
\end{aligned}
$$

By the lemma, there exists a polynomial $P_{n}(x)$ of degree $\leqq n$, such that

$$
\begin{aligned}
\max _{a \leq x \leqq b} \mid & f(x)-P_{n}(x) \mid \\
& \leqq\left(1+\frac{\pi}{4}\right)\left[\frac{\pi}{4}(b-a)\right]^{p}\left[\prod_{\nu=0}^{p-1}(n+1-\nu)\right]^{-1} w\left(\frac{b-a}{n-p+1}\right) .
\end{aligned}
$$

This completes the proof.

\section{References}

1. N. Ahiezer and M. Krein, On the best approximation of differentiable periodic functions by trigonometric sums (Russian), Doklady Akad. Nauk SSSR, XV (1937), 107-112. 
2. J. Favard, Sur les meilleurs procédés d'approximation de certaines classes de fonctions par des polynomes trigonométriques, Bull. des Sciences Math. LXI (1937), 209-224, 243-256, in particular pp. 219, 220, and 223.

3. D. Jackson, The theory of approximation, Amer. Math. Soc. Colloq. Publ. Vol. XI, New York, 1930.

Aerospace Research Laboratories, Wright-Patterson aFB, Ohio AND

National Bureau of Standards, Washington, D. C. 



\title{
PACIFIC JOURNAL OF MATHEMATICS
}

\author{
EDITORS
}

\author{
H. Samelson \\ Stanford University \\ Stanford, California \\ R. M. Blumenthal \\ University of Washington \\ Seattle, Washington 98105
}

\author{
J. DugundjI \\ University of Southern California \\ Los Angeles, California 90007 \\ Richard Arens \\ University of California \\ Los Angeles, California 90024
}

\section{ASSOCIATE EDITORS}
E. F. BECKENBACH
B. H. NEUMaNN
F. WOLF
K. YosIDA

\section{SUPPORTING INSTITUTIONS}

\author{
UNIVERSITY OF BRITISH COLUMBIA \\ CALIFORNIA INSTITUTE OF TECHNOLOGY \\ UNIVERSITY OF CALIFORNIA \\ MONTANA STATE UNIVERSITY \\ UNIVERSITY OF NEVADA \\ NEW MEXICO STATE UNIVERSITY \\ OREGON STATE UNIVERSITY \\ UNIVERSITY OF OREGON \\ OSAKA UNIVERSITY \\ UNIVERSITY OF SOUTHERN CALIFORNIA
}

\author{
STANFORD UNIVERSITY \\ UNIVERSITY OF TOKYO \\ UNIVERSITY OF UTAH \\ WASHINGTON STATE UNIVERSITY \\ UNIVERSITY OF WASHINGTON \\ AMERICAN MATHEMATICAL SOCIETY \\ CALIFORNIA RESEARCH CORPORATION \\ SPACE TECHNOLOGY LABORATORIES \\ NAVAL ORDNANCE TEST STATION
}

Mathematical papers intended for publication in the Pacific Journal of Mathematics should by typewritten (double spaced). The first paragraph or two must be capable of being used separately as a synopsis of the entire paper. It should not contain references to the bibliography. Manuscripts may be sent to any one of the four editors. All other communications to the editors should be addressed to the managing editor, Richard Arens, at the University of California, Los Angeles, California 90024.

50 reprints per author of each article are furnished free of charge; additional copies may be obtained at cost in multiples of 50 .

The Pacific Journal of Mathematics is published quarterly, in March, June, September, and December. Effective with Volume 13 the price per volume (4 numbers) is $\$ 18.00$; single issues, $\$ 5.00$. Special price for current issues to individual faculty members of supporting institutions and to individual members of the American Mathematical Society: $\$ 8.00$ per volume; single issues $\$ 2.50$. Back numbers are available.

Subscriptions, orders for back numbers, and changes of address should be sent to Pacific Journal of Mathematics, 103 Highland Boulevard, Berkeley 8, California.

Printed at Kokusai Bunken Insatsusha (International Academic Printing Co., Ltd.), No. 6, 2-chome, Fujimi-cho, Chiyoda-ku, Tokyo, Japan.

PUBLISHED BY PACIFIC JOURNAL OF MATHEMATICS, A NON-PROFIT CORPORATION

The Supporting Institutions listed above contribute to the cost of publication of this Journal, but they are not owners or publishers and have no responsibility for its content or policies. 


\section{Pacific Journal of Mathematics}

\section{Vol. 15, No. $2 \quad$ October, 1965}

Patrick Robert Ahern, On the generalized F. and M. Riesz theorem......... 373

A. A. Albert, On exceptional Jordan division algebras ................ 377

J. A. Anderson and G. H. Fullerton, On a class of Cauchy exponential

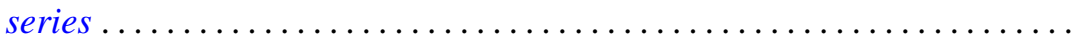

Allan Clark, Hopf algebras over Dedekind domains and torsion in

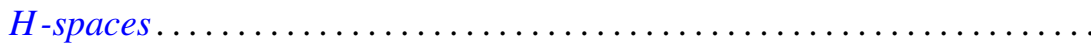

John Dauns and D. V. Widder, Convolution transforms whose inversion functions have complex roots .............................

Ronald George Douglas, Contractive projections on an $\mathrm{L}_{1}$ space ..........

Robert E. Edwards, Changing signs of Fourier coefficients ...............

Ramesh Anand Gangolli, Sample functions of certain differential processes on symmetric spaces .....................................

Robert William Gilmer, Jr., Some containment relations between classes of

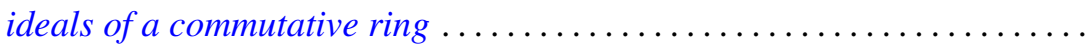

Basil Gordon, A generalization of the coset decomposition of a finite

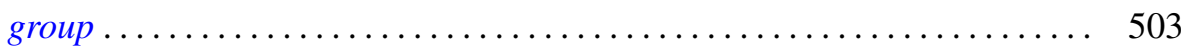

Teruo Ikebe, On the phase-shift formula for the scattering operator....... 511

Makoto Ishida, On algebraic homogeneous spaces ................ 525

Donald William Kahn, Maps which induce the zero map on homotopy ........ 537

Frank James Kosier, Certain algebras of degree one ................. 541

Betty Kvarda, An inequality for the number of elements in a sum of two sets of lattice points.................................

Jonah Mann and Donald J. Newman, The generalized Gibbs phenomenon for regular Hausdorff means. .

Charles Alan McCarthy, The nilpotent part of a spectral operator. II . ...

Donald Steven Passman, Isomorphic groups and group rings ...

R. N. Pederson, Laplace's method for two parameters .....

Tom Stephen Pitcher, A more general property than domination for sets of probability measures .............................

Arthur Argyle Sagle, Remarks on simple extended Lie algebras. .

Arthur Argyle Sagle, On simple extended Lie algebras over fields of

characteristic zero.

Tôru Saitô, Proper ordered inverse semigroups ...........

Oved Shisha, Monotone approximation

Indranand Sinha, Reduction of sets of matrices to a triangular form

Raymond Earl Smithson, Some general properties of multi-valued

functions .................................

John Stuelpnagel, Euclidean fiberings of solvmanifolds .... 